appropriate surgical techniques. Depending on the clinical situation and judgment, a Fogarty maneuver can also be performed at this stage, eventually making use of the cannula insertion side. The wound is drained and closed in the usual manner.

\section{RESULTS}

We applied this technique in 3 male patients $(62 \pm 6$ years). Of these, 2 required salvage and 1 urgent preventive venoarterial ECMO support in the catheterization laboratory. All presented with cardiogenic shock due to STsegment elevation myocardial infarction. All underwent percutaneous transluminal coronary angioplasty of the proximal left anterior descending artery or the main stem of the left coronary artery. Perfusion cannulas (18F and 24F) were introduced percutaneously through the already wired groin vessels. Transformation to a transprosthetic cannulation was performed in all cases, either electively at the end of the percutaneous transluminal coronary angioplasty or after disappearance of the peripheral pulses (by Doppler ultrasonography) 8 and 22 hours after initiation of the venoarterial ECMO (urgent transformation). In neither cases were there any clinical signs of manifest tissue ischemia and no thrombotic material was retrieved from the peripheral arterial branches; relief fasciotomy was therefore not performed.

\section{DISCUSSION}

Prevention of distal limb ischemia is a clinical priority after percutaneous institution of venoarterial ECMO. The adequacy of the arterial perfusion distal to the cannulation site can be monitored clinically and by means of Doppler ultrasonography. Adequate arterial perfusion to the distal limb should be established as soon as possible to prevent the deleterious consequences of distal limb ischemia.

Current techniques for distal perfusion after peripheral arterial cannulation $^{2-5}$ consist of the introduction of an additional perfusion catheter in the distal artery. The effective distal perfusion flow can be inadequate, however, because it is determined by the resistance of the stopcock connection of the perfusion catheter to the circuit and of the catheter itself. After decannulation, the artery is left with two openings requiring care. The surgical technique proposed here ensures adequate distal perfusion, prepares a safe decannulation and stenosis-free reconstruction of the artery, and gives the surgeon the chance to reconstruct the insertion hole of the percutaneous cannula or the possibility of performing an embolectomy of the distal femoral arteries under undisturbed ECMO perfusion. This technique should be seen as an enrichment of the armamentarium and lower the threshold for a proactive approach toward prevention of distal limb ischemia in critically ill patients placed on percutaneous venoarterial ECMO.

\section{References}

1. Bisdas T, Beutel G, Warnecke G, Hoeper MM, Kuehn C, Haverich A, et al. Vascular complications in patients undergoing femoral cannulation for extracorporeal membrane oxygenation support. Ann Thorac Surg. 2011;92:626-31.

2. Greason KL, Hemp JR, Maxwell JM, Fetter JE, Moreno-Cabral RJ. Prevention of distal limb ischemia during cardiopulmonary support via femoral cannulation. Ann Thorac Surg. 1995;60:209-10.

3. Huang SC, Yu HY, Ko WJ, Chen YS. Pressure criterion for placement of distal perfusion catheter to prevent limb ischemia during adult extracorporeal life support. J Thorac Cardiovasc Surg. 2004;128:776-7.

4. Madershahian N, Nagib R, Wippermann J, Strauch J, Wahlers T. A simple technique of distal limb perfusion during prolonged femoro-femoral cannulation. J Card Surg. 2006;21:168-9.

5. Russo CF, Cannata A, Vitali E, Lanfranconi M. Prevention of limb ischemia and edema during peripheral venoarterial extracorporeal membrane oxygenation in adults. J Card Surg. 2009;24:185-7.

\title{
Correction of pectus excavatum through a minimally invasive approach with subxyphoid incision and 3-point fixation
}

\author{
Sheldon J. Bond, MD, and Hirikati S. Nagaraj, MD, Louisville, Ky \\ From the Division of Pediatric Surgery, Department of Surgery, University of \\ Louisville School of Medicine, Louisville, Ky. \\ Disclosures: Authors have nothing to disclose with regard to commercial support. \\ Received for publication March 28, 2013; revisions received May 2, 2013; accepted \\ for publication July 8, 2013; available ahead of print Aug 28, 2013. \\ Address for reprints: Sheldon J. Bond, MD, Division of Pediatric Surgery, Depart- \\ ment of Surgery, University of Louisville School of Medicine, 315 E Broadway \\ St, Suite 565, Louisville, KY 40202 (E-mail: sjbond01@louisville.edu). \\ J Thorac Cardiovasc Surg 2013;146:1294-6 \\ $0022-5223 / \$ 36.00$ \\ Copyright (c) 2013 by The American Association for Thoracic Surgery \\ http://dx.doi.org/10.1016/j.jtcvs.2013.07.014
}

The development of the minimally invasive technique known as the Nuss procedure for pectus excavatum has clearly been a benefit to children with this chest wall deformity. ${ }^{1}$ There have already been several modifications, and certainly additional modifications will be developed as the technique continues to be implemented. Many of these modifications have been developed in response to procedural complications. Cardiac and aortic lacerations have been described after minimally invasive repair of pectus excavatum. ${ }^{2}$ Proposed solutions have included a subxyphoid 
incision with sternal elevation to lift the chest wall away from the heart. ${ }^{3}$

An additional concern is bar displacement, the rate of which was initially $15 \%$ and is now $5 \%$ to $10 \%$ in most series. ${ }^{1}$ This complication is age dependent, however, and was noted by one group to occur in $8.3 \%$ of adolescents and $33.3 \%$ of adults. ${ }^{4}$ Methods designed to prevent bar displacement include the use of multiple bars, bar stabilizers, and 3-point fixation. ${ }^{5,6}$

In an effort to limit both cardiac perforation and bar displacement, we have created and describe an approach that uses a subxyphoid incision with central fixation to the costal margins.

\section{DESCRIPTION OF TECHNIQUE}

The indications for surgical intervention in patients with pectus excavatum have been well documented. ${ }^{1}$ Selection is based on clinical symptoms, Haller Index, and echocardiography.

The patient is placed under general anesthesia, usually with an epidural analgesic catheter in place. The deepest part of the chest is marked. An appropriate interspace is chosen for the lateral entry point of the pectus bar, and lateral incisions are performed. In addition, a central incision is made in the subxyphoid location and a retrosternal tunnel is developed. When one passes the large Kelly clamp from the lateral incision towards the mediastinum, a finger in the retrosternal tunnel can actually help to guide that clamp and lift the sternum to increase the space between the chest wall and the vital structures. Umbilical tapes are then passed from the subxyphoid incision to the left chest incision and then from the subxyphoid incision to the right chest incision. The umbilical tapes at this point traverse the chest cavity. The pectus dilators are passed before the customized pectus bar itself. Just before the passage of the customized bar, we place 2 \#1 polydioxanone sutures around the umbilical tape through the subxyphoid incision (Figure 1). The customized pectus bar is then passed, and at that point the sutures are around the bar and are adjusted to a central location (Figure 2). Often, as seen in Figure 2, the centrally placed sutures catch in the pectus bar notches and are displaced to the lateral incision on the side to which the bar is being pulled. Release of these sutures and pulling on them through the subxyphoid incision will relocate the sutures around the bar in the midline. In this fashion, after the bar is secured laterally, the central sutures can now be sutured to the costal margin medially and provide 3-point fixation. Most bar displacements are cephalad, and this downward central fixation around the middle portion of the bar will add resistance to such displacement. This technique has been used successfully in more than 80 patients to date.

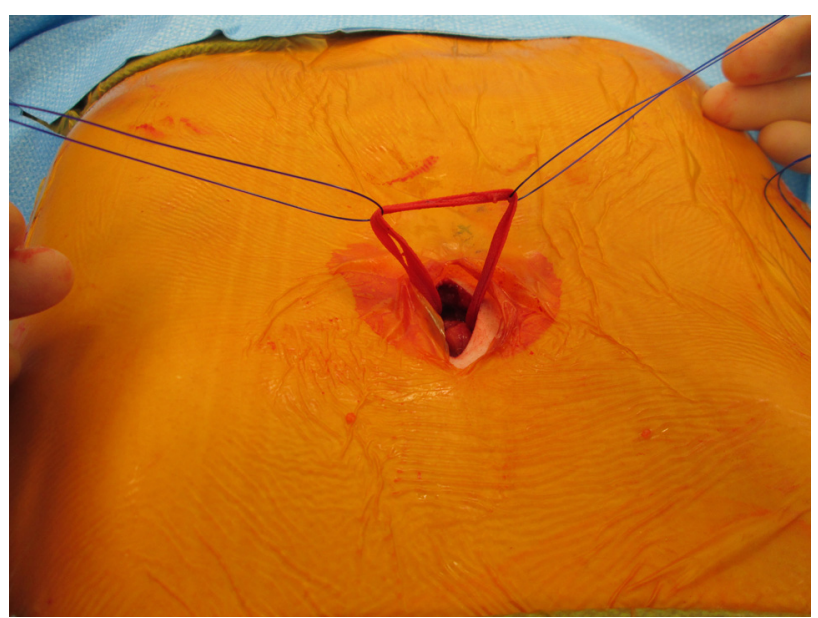

FIGURE 1. Sutures are placed through a subxyphoid incision around transthoracic umbilical tapes.

\section{DISCUSSION}

Initially, we performed this technique with 2 lateral incisions and thoracoscopy, as it was originally developed. We later used a central incision with a retrosternal tunnel, so we could actually feel the clamp as it passed from the lateral incisions to the midline. The latter is now our preferred approach. Additional modification with central fixation is added to prevent bar displacement. An absorbable suture is used, because most displacements occur in the first month after the operation. ${ }^{6}$ This central fixation provides stability during the early postoperative period and thus limits the possibility of displacement before natural scarring has had time to occur. It would certainly be expected that 3-point fixation, both lateral and central fixation, would be superior to 2-point fixation only.

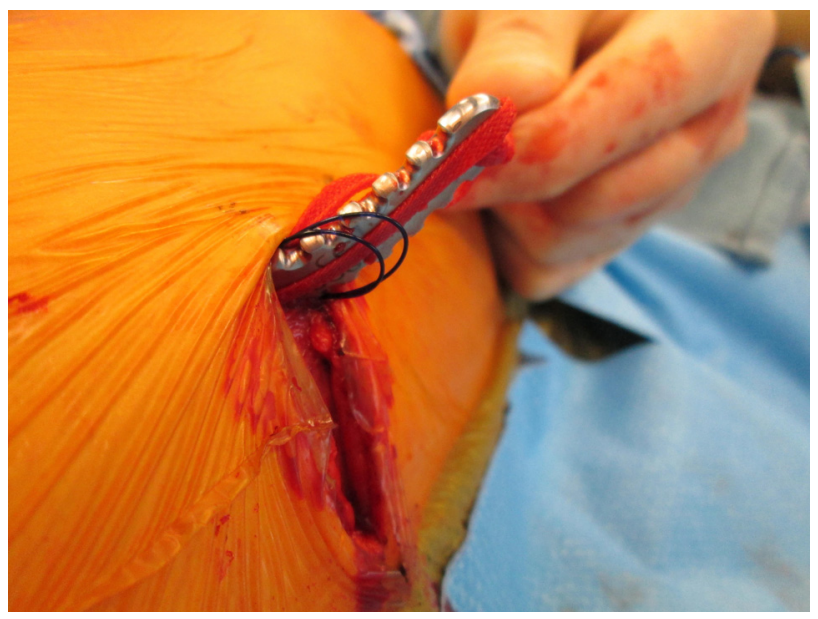

FIGURE 2. The pectus bar is pulled through the chest. Subxyphoid sutures are pulled to a lateral incision by bar notches. Releasing the suture from the notches with subxyphoid tension on the sutures restores them to the midline for subsequent suturing to the costal margins. 


\section{CONCLUSIONS}

We have combined the idea of a central incision to provide safer passage of the pectus bar with that of 3-point fixation to limit displacement of the pectus bar to create a modification of the Nuss procedure, with success in more than 80 cases.

\section{References}

1. Nuss D. Minimally invasive surgical repair of pectus excavatum. Semin Pediatr Surg. 2008;17:209-17
2. Ohno K, Nakamura T, Azuma T, Yamada H, Hayashi H, Masahata K. Modification of the Nuss procedure for pectus excavatum to prevent cardiac perforation. J Pediatr Surg. 2009;44:2426-30.

3. Johnson WR, Fedor D, Singhal S. A novel approach to eliminate cardiac perforation in the Nuss procedure. Ann Thorac Surg. 2013;95:1109-11.

4. Kim do H, Hwang JJ, Lee MK, Lee DY, Paik HC. Analysis of the Nuss procedure for pectus excavatum in different age groups. Ann Thorac Surg. 2005;80: 1073-7.

5. Tedde ML, Campos JR, Das-Neves-Pereira JC, Abrāo FC, Jatene FB. The search for stability: bar displacement in three series of pectus excavatum patients treated with the Nuss technique. Clinics (Sao Paulo). 2011;66:1743-6.

6. Hebra A, Gaudere MW, Tagge EP, Adamson WT, Othersen HB Jr. A simple technique for preventing bar displacement with the Nuss repair of pectus excavatum. J Pediatr Surg. 2001;36:1266-8

\title{
Reconstructive options for gastroesophageal junction adenocarcinoma after Roux-en-Y gastric bypass
}

\author{
Afif N. Kulaylat, MD, Sunny Sahajwani, MD, MHS, Kevin F. Staveley-O'Carroll, MD, PhD, and \\ Jussuf T. Kaifi, MD, PhD, Hershey, Pa
}

In Western countries, esophagogastric cancers have migrated toward the gastroesophageal junction (GEJ), with adenocarcinoma the predominating histologic type. GEJ cancers are the fastest growing cancers in the United States. ${ }^{1,2}$ Cancer development after Roux-en-Y gastric bypass (RNYGB) is not well characterized. Altered anatomy poses technical challenges for surgical resection. We report our reconstructive experience with GEJ adenocarcinoma diagnosed after RNYGB.

\section{CLINICAL SUMMARIES}

Between 2008 and 2012, a total of 271 consecutive patients underwent resection with curative intent for GEJ adenocarcinoma at our institution. Two patients $(0.7 \%)$ were encountered with GEJ cancers after RNYGB and reviewed with institutional review board approval.

\section{Patient 1}

A 62-year-old man (body mass index [BMI], $40 \mathrm{~kg} / \mathrm{m}^{2}$ ) with history of smoking and gastroesophageal reflux disease who had undergone RNYGB 6 years earlier

\footnotetext{
From the Program for Liver, Pancreas, and Foregut (Lung and Esophageal) Tumors, Section of Surgical Oncology, Department of Surgery, Penn State Milton S. Hershey Medical Center, Hershey, Pa.

Disclosures: Authors have nothing to disclose with regard to commercial support.

Received for publication March 5, 2013; revisions received April 15, 2013; accepted for publication July 9, 2013; available ahead of print Aug 28, 2013.

Address for reprints: Afif N. Kulaylat, MD, Section of Surgical Oncology, Department of Surgery, Penn State Milton S. Hershey Medical Center, Hershey, PA 17033 (E-mail: akulaylat@hmc.psu.edu).

J Thorac Cardiovasc Surg 2013;146:1296-8

0022-5223/\$36.00

Copyright (c) 2013 by The American Association for Thoracic Surgery

http://dx.doi.org/10.1016/j.jtcvs.2013.07.007
}

(initial BMI, $60 \mathrm{~kg} / \mathrm{m}^{2}$ ) was seen for epigastric pain and gastrointestinal bleeding. Evaluation by esophagogastroduodenoscopy and endoscopic ultrasonography with biopsy demonstrated poorly differentiated invasive adenocarcinoma of the distal esophagus (Siewert type I) with periesophageal and gastric lymph node involvement. Neoadjuvant chemoradiation achieved moderate response, as seen on positron emission tomography and computed tomography (CT). He subsequently underwent an open transhiatal complete esophagectomy with gastric pouchectomy. The proximal alimentary Roux limb was resected, with a gastric conduit fashioned from the remnant. Continuity was restored by jejunojejunostomy (abandoning the Roux-en$\mathrm{Y}$ ), and a cervical esophagogastrostomy was created (Figure 1). Pathology showed a completely resected T3N1 adenocarcinoma. He received adjuvant chemotherapy (subsequent BMI, $32 \mathrm{~kg} / \mathrm{m}^{2}$ ). Recurrent disease was discovered in his liver on surveillance positron emission tomography and CT after 15 months, and his overall survival after resection was 19 months.

\section{Patient 2}

A 54-year-old woman (BMI, $34 \mathrm{~kg} / \mathrm{m}^{2}$ ) with a history of smoking and gastroesophageal reflux disease who had undergone RNYGB 7 years earlier (initial BMI, $55 \mathrm{~kg}$ / $\mathrm{m}^{2}$ ) had dysphagia and weight loss. Esophagogastroduodenoscopy revealed a $2-\mathrm{cm}$ gastric pouch ulcer, with biopsy demonstrating a poorly differentiated adenocarcinoma (Siewert type III). Intraoperatively, the cancer invaded the remnant stomach from the gastric pouch. With en bloc resection of the remnant, a total gastrectomy was performed, leaving a duodenal stump. The previous Roux 